\title{
Sib Converter with Reduced Harmonic Distortion Using Fuzzy Logic Controller
}

\author{
N.Karthik \\ EEE, Hindustan University, India
}

\begin{abstract}
An integrated conventional boost converter and a single ended primary inductor converter (SEPIC) using Fuzzy Logic Controller is presented on this paper. By use of classical boost converter, it contains insufficient step-up ratio, distribution of voltage stress is complex. It needs snubber circuit for additional protection. However, it is very difficult to satisfy both high voltage conversion ratio and high efficiency at once. As a solution to supplement the insufficient step-up ratio and distribute a voltage stress of a classical boost converter, a Sepic-integrated boost (SIB) converter, which provides an additional step-up gain with the help of an isolated Sepic converter using Fuzzy Logic Controller, is proposed. The main advantages a simple structure, continuous input current, and clamped switch voltage stress to the output voltage.
\end{abstract}

Keywords: Boost converter, Sepic converter. Sepic integrated Boost (SIB) converter, harmonic reduction, fuzzy logic controller.

\section{Introduction}

The boost converter is the usual structure utilized in high-power-factor (HPF) rectifiers in order to improve power factor (PF) and reduce the total current harmonic distortion (THD). However, for universal input voltage application, the efficiency can be reduced mainly in the lowest input voltage, and the worst operation condition must be considered in the power converter design procedure [1]. The improvement of the efficiency at lower line voltage is important because the thermal design and heat sinks size are defined considering the worst operation point. Many works were developed in order to improve the operation characteristics of the power converter utilized in HPF universal input rectifiers.

The non-isolated high step-up conversion technique finds increasing necessities in applications, such as electric vehicles, uninterrupted power supplies (UPS), high-intensity discharge (HID) lamp, fuel cell system, and photovoltaic systems.

\section{Converter Description}

The basic converter topologies such as the Buck, Boost, Fly back, SEPIC, Cuk, and others, have long been attractive and are often chosen for implementing simple, low cost, and low power converters. The use of a single active switch with relatively simple control circuitry is a strong reason for this choice [2].The buck and the boost converters with an input or output filter results in a more bulky converter when compared to the Cuk converter. This is because the input and output inductor cannot be coupled into a single magnetic core as in the Cuk converter ,hence, it increases the overall cost and board area required, which is an undesirable for many applications[1].

For applications which require low ripple current at the input and output port of the converter, the Cuk converter seems to be a potential candidate in the basic converter topologies. The fly back converter requires an additional input and output $\mathrm{L}-\mathrm{C}$ filter to reduce the switching ripple and noise level at both terminals. The major disadvantage of the Cuk topology besides its inverting output polarity is that both the power switch and the output diode must carry significantly higher currents than typically encountered in other topologies. The potential voltage and current stresses imposed on both the power switch and the diode force the circuit designer to use overrated components [2].

On the other hand, the SEPIC converter was developed primarily to have step up/down capability without inverting the polarity of the regulated output voltage. Actually, both SEPIC and Cuk converters present very similar characteristics and they have the same semiconductor voltage and current stresses [4]. Both configurations offer easy implementation of transformer isolation. It has also been shown that both converters have advantages over the boost converter in terms of the conducted electromagnetic interference noise[1]. 


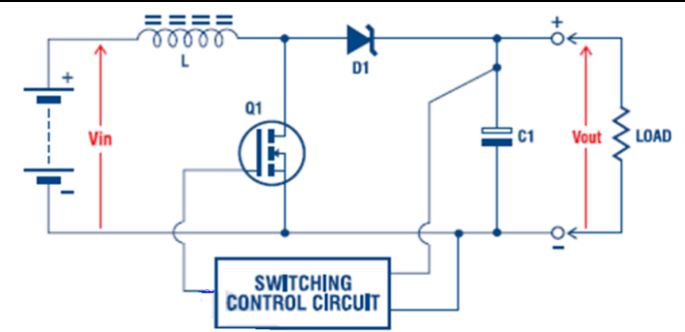

Fig.1 Conventional Boost converter

The power circuit of the classical SEPIC converter is presented in Fig. 2. Moreover, in high output voltage applications, a high-voltage rating diode causes a severe reverse recovery problem, which requires a snubber circuit. As a result, a general boost converter would not be acceptable for high step-up applications. To overcome these limitations, various types of step-up converters, utilizing the voltage conversion ability of a transformer, a coupled-inductor, and a multiplier cell, can be adopted [1].

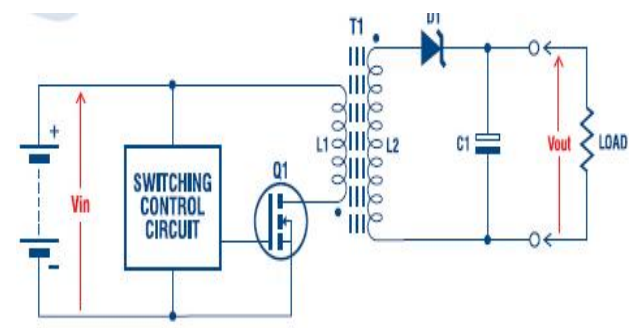

Fig.2 Conventional SEPIC converter

\section{Proposed Converter}

The step-up and step-down static gain of the SEPIC converter is an interesting operation characteristic for a wide input voltage range application. However, as the switch voltage is equal to the sum of the input and output voltages, this topology is not used for a universal input HPF rectifier. Current-fed type converters, which easily offer a high step-up ratio using a transformer, are attractive for high power step-up applications with multiple switches [2]. However, they require snubber to limit the voltage spike across switches caused by the existence of transformer leakage inductance, resulting in an additional loss. Moreover, an auxiliary circuit is needed for below 0.5 duty operation and the input current is no longer continuous in this operation [5]. Active clamp approaches release these problems and reduce switching losses, but lead to complex structures with increased number of switches.

A coupled-inductor-employed boost converter is also a favorable candidate in low-to-medium power applications for its simple structure; though the input current is not continuous as in a general boost converter and an auxiliary circuit is also required to suppress the switch voltage spike [1], [2].As the output voltage is increased, however, the number of stage is increased, requiring more capacitors and diodes. Besides, the current snubber is required to reduce the reverse recovery on diode.

To simplify the circuit, a boost converter and a Sepic converter, as a series output module can be simply integrated, as shown in Fig. 2, because they can share common parts, i.e., a boost inductor LB and a switch Q. Since this series output module should have a floating output ground, an isolated-type Sepic converter is adopted.

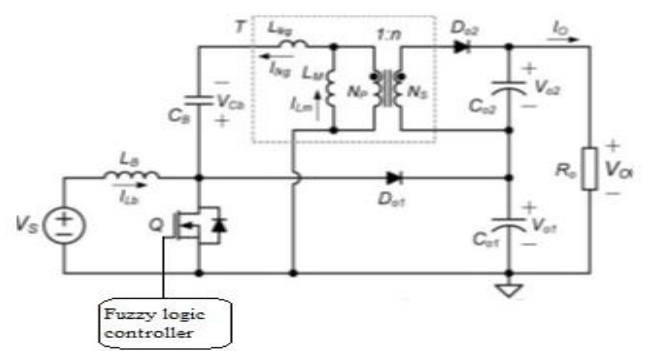

Fig.3 SEPIC Integrated Boost (SIB) converter using Fuzzy Logic Controller.

As a result, a Sepic-integrated boost (SIB) converter is derived, as shown in Fig. 3. This converter provides an additional step-up ratio and a distributed voltage stress on devices, while maintaining the advantages of the boost converter, such as continuous input current and clamped voltage stress on switch. 
Moreover, the transformer leakage inductance provides a current snubbing effect, which alleviates the reverse recovery problem on diodes.

\section{Operation Principles}

SEPIC is a type of DC -DC converter that allows the electrical potential (voltage) at its output to be greater than, less than, or equal to that at its input; the output of the SEPIC is controlled by the duty cycle of the control transistor. A SEPIC is similar to a traditional buck-boost converter, but has advantages of having noninverted output (the output voltage is of the same polarity as the input voltage), the isolation between its input and output (provided by a capacitor in series).

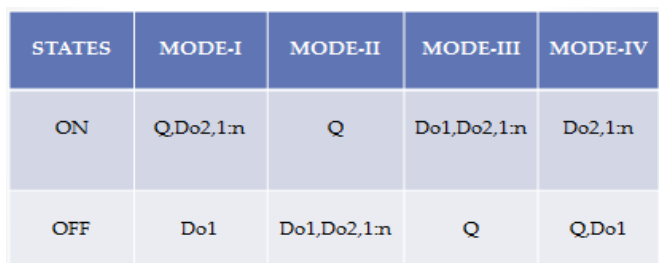

This paper has presented a modified SEPIC converter with a continuous output current. The principle of operation and the design-oriented analysis of the proposed converter have been presented. Normalized expressions for peak component stresses are also given, which allow the design optimization of the power stage.

A comparison between the proposed topology and the conventional SEPIC converter shows that the components current stresses are much lower in the presented topology.

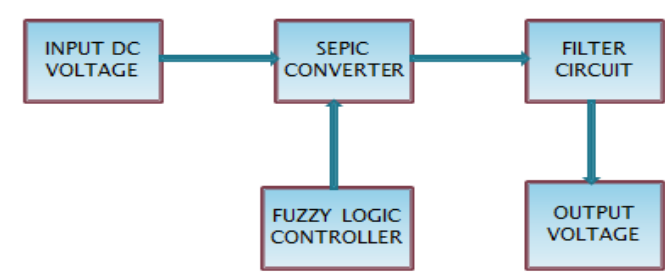

Fig.4 Block Diagram of SEPIC converter.

hus, in low-voltage high-current applications, the proposed topology can be more beneficial than a conventional SEPIC converter. Furthermore, this study also shows that the output capacitor current ripple is greatly reduced when compared to the conventional SEPIC, which in turn minimizes the converter's output capacitance requirements.

\section{Mathematical Analysis}

The SEPIC is a DC to DC topology similar to the Cuk converter. It is capable of stepping up or down the input voltage; it has an input inductor and a capacitor for an energy transfer device [2]. The difference is that the output of the converter is reconfigured so that the output voltage has the same polarity as the input voltage. The SEPIC topology is shown in Fig 2.

$$
\begin{gathered}
\frac{\mathrm{dIL} L_{1}}{\mathrm{dt}}=\frac{\mathrm{Vin}}{\mathrm{L}_{1}}+\frac{\mathrm{Vc}_{1}+\mathrm{Vc}_{\mathrm{C}_{2}}}{\mathrm{~L}_{2}}(\mathrm{~S}-1) \\
\frac{\mathrm{dIL_{1 }}}{\mathrm{dt}}=\frac{\mathrm{Vc}_{1}}{\mathrm{~L}_{2}} \mathrm{~S}+\frac{\mathrm{V}_{0}}{\mathrm{~L}_{2}}(\mathrm{~S}-1) \\
\frac{\mathrm{dVc_{1 }}}{\mathrm{dt}}=\frac{\mathrm{IL}_{1}}{\mathrm{C}_{1}} \cdot(1-\mathrm{S})-\frac{\mathrm{IL} 2}{\mathrm{C}_{1}} \mathrm{~S} \\
\frac{\mathrm{dVc_{2 }}}{\mathrm{dt}}=\frac{\mathrm{IL}_{1}+\mathbb{I L}_{2}}{\mathrm{C}_{2}} \cdot(1-\mathrm{S})-\frac{\mathrm{I}_{0}}{\mathrm{C}_{2}}
\end{gathered}
$$

Performing a similar procedure to find the relationship of input and output voltage of the Boost converter, the SEPIC relationship is:

$$
\frac{V_{0}}{V_{i n}}=\frac{D}{1-D}
$$




\section{Simulation Results}

To illustrate the design procedure for a $200-\mathrm{W}$ prototype converter with $42 \mathrm{~V}$ input and $400 \mathrm{~V}$ output operating at $60 \mathrm{kHz}$, an example is presented as follows. The required input-output voltage gain Mis 9.52 $(=400 / 42)$, i.e., about 10 .

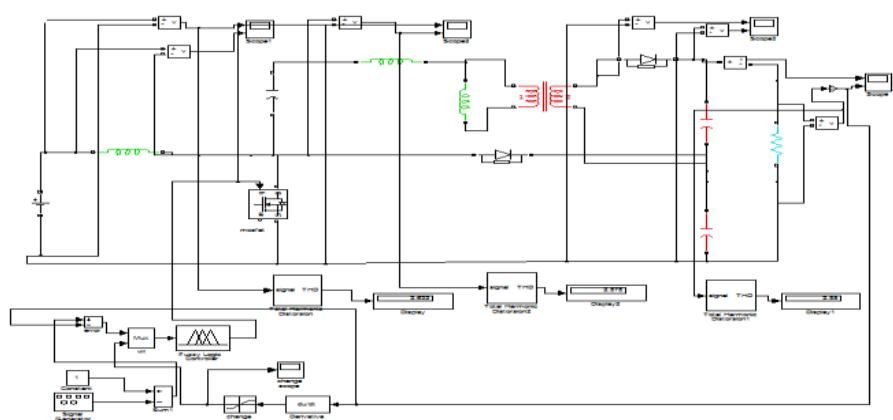

Fig.5 Simulation circuit for Sepic Integrated Boost (SIB) converter using Fuzzy Logic Controller.

To distribute and limit the voltage stress across the diode in the Sepic converter by Vo2 with a nondissipative way, the secondary side is substituted by the clamp diode structure. Therefore, the nominal duty cycle Dnom should be selected as above 0.5. In the converter design, a selection of the switch Q, which is burdened by the large input current ILb and ILm as well, is primarily considered with respect to the cost and the efficiency. Therefore, a D should be selected to accommodate as a low voltage stress as possible, while still having a low rms value of a switch current. To utilize a $200 \mathrm{~V}$ switch with a sufficient margin, therefore, the Dnom is selected as about 0.6 .

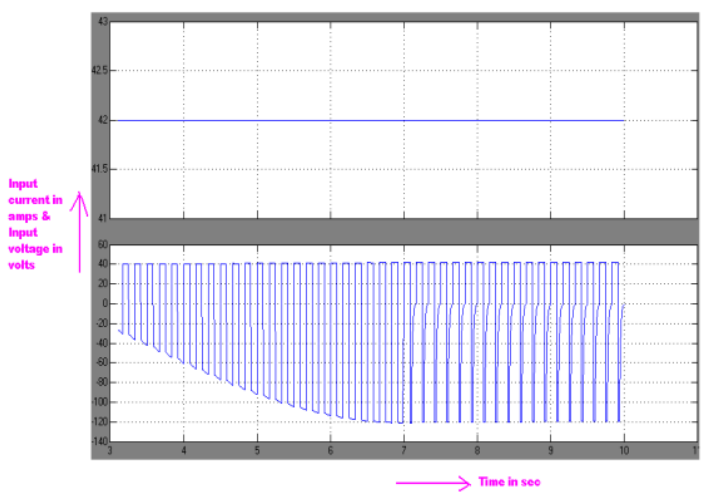

Fig.6 Input voltage and input current of SIB converter using Fuzzy Logic Controller.

An rms value of switch current is decreased as D is increased. That is, a larger D is of benefit for reducing a switch conduction loss. However, a switch voltage stress VS /(1-D) is increased in return, which lead to a use of higher voltage switch having larger ON-resistance.

The SIB converter can achieve a high-voltage gain with the additional step-up ability of the isolated Sepic converter and distributed voltage stress, while maintaining the advantages of the boost converter, such as a continuous input current and a clamped voltage stress on switch.

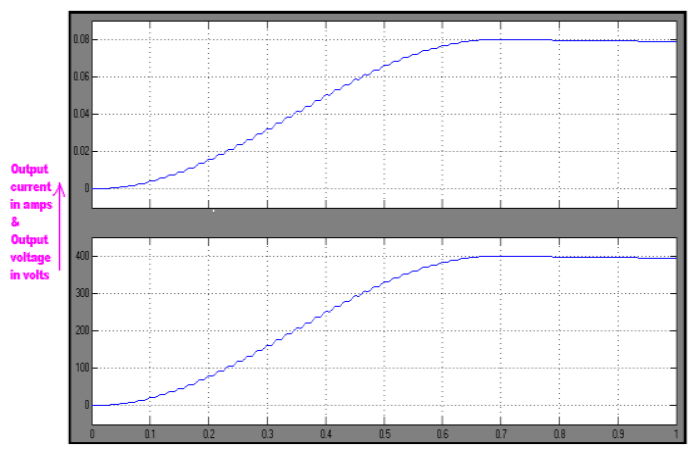

Fig.7 Output voltage and output current of SIB converter using Fuzzy Logic Controller. 
To verify the performance of the proposed control strategy, a MATLAB-SIMULINK prototype of the SEPIC Integrated Boost (SIB) converter is developed. To illustrate the design feasibility of the proposed converter, a prototype with the following specifications is chosen.

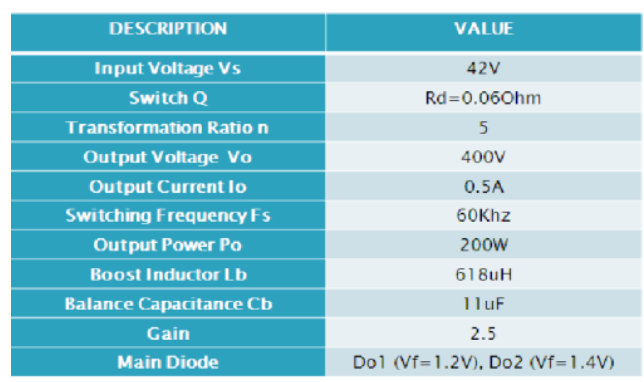

TABLE-II

Total Harmonic Distrotion Analysis

Total Harmonic Distortion (or Distortion Factor) of voltage or current is the ratio of the RMS value of harmonics above fundamental, divided by the RMS value of the fundamental.

The THD value in this table is expressed as a function of the nominal system RMS voltage rather than of the fundamental frequency voltage magnitude at the time of the measurement.

The performance of the modified SEPIC converter is compared with the classical boost converter. The experimental waveforms are obtained with the experimental prototype operating with the nominal output power $\mathrm{Po}=200 \mathrm{~W}$ and $\mathrm{THD}=28.31 \%$. The output voltage is regulated in $\mathrm{Vo}=400 \mathrm{Vdc}$.

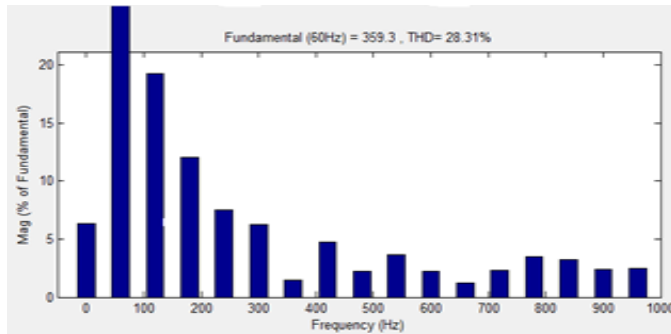

Fig.7 The presence of Total Harmonic Distortion in the Output voltage using Fuzzy Logic Controller.

\section{Conclusion}

For non-isolated high step-up applications, the SIB converter, which combines a boost converter and an isolated sepic converter with one switch, is introduced in this paper. The SIB converter can achieve a highvoltage gain with the additional step-up ability of the isolated sepic converter and distributed voltage stress, while maintaining the advantages of the boost converter, such as a continuous input current and a clamped voltage stress on switch and maintain the low THD value on the output voltage waveform using fuzzy logic controller compared with the PWM gate pulse given to the switch Q.

Moreover, the reverse recovery problem is well suppressed, since the transformer leakage inductance alleviates a di/dt ratio of the turn-off diode current without additional snubber and the voltage stress on the secondary diode is limited by the clamp diodes. It is noted that other converters, which have a boost inductor and a switch as an input stage, can also be integrated with the boost converter similar to the SIB converter. By using the PWM controller gate pulse the presence of THD on the output side will be THD $=31.07 \%$, and by use of Fuzzy logic controller as the pulse of the switch Q, the presence of THD on the output side will be $\mathrm{THD}=28.31 \%$.

\section{References}

[1]. M. A. Al-Saffar, "An improved topology of SEPIC converter with reduced output voltage ripple," IEEE Trans. Power Electron., vol. 23, no. 5, pp. 2377-2386, Sep. 2008.

[2]. Paolo Mattavelli" General-Purpose Fuzzy Controller for DC-DC Converters", IEEE Trans. Power Electron. vol. 12, no. 1, pp. 7986, May. 1995.

[3]. Henry Shu-Hung Chung" A Novel Maximum Power Point Tracking Technique for Solar Panels Using a SEPIC or Cuk Converter," IEEE Trans. Power Electron. vol. 18, no. 3, pp. 717-724, May. 2003.

[4]. Edy E. Jiménez-Toribio" Sensorless Control of SEPIC and Cuk Converters for DC Motors using Solar Panels," IEEE Trans. Power Electron.2009.

[5]. Simone Buso" Simplified Control Technique for High-Power-Factor Flyback Cuk and Sepic Rectifiers Operating in CCM," IEEE Trans. Power Electron. vol. 36, no.5, pp. 1413-2000, Sep. 2000. 